\title{
Polysplenia Syndrome with Common Atrioventricular Canal and Persistent Truncus Arteriosus
}

\author{
Hirokazu Arai, Kenji Harada, Masamichi Tamura, \\ Toshiniro OKamura* and Goro Takada \\ Department of Pediatrics, Akita University School of \\ Medicine, Akita 010, and *Yuri General Hospital, Honjo \\ 015
}

Arai, H., Harada, K., Tamura, M., Okamura, T. and Takada, G. Polysplenia Syndrome with Common Atrioventricular Canal and Persistent Truncus Arteriosus. Tohoku J. Exp. Med., 1995, 177 (2), 171-177_— A case of an infant with a rare combination of polysplenia syndrome with common atrioventricular canal and persistent truncus arteriosus is presented. In our present case, severe common atrioventricular valve regurgitation was identified, as in previous cases. To our knowledge, echocardiographic and autopsy findings of this association has not been previously reported. The persistent truncus arteriosus is extremely rare in the setting of the polysplenia syndrome, but the present case report demonstrates that these anomalies may, at times, occur. —— polysplenia; persistenttruncus arteriosus; common atrioventricular canal

In the polysplenia syndrome, multiple anomalies of the heart and viscera are present. Cardiac anomalies are found in most patients and typically are interruption of the inferior vena cava with azygos connection, partial anomalous pulmonary venous connection, common atrioventricular canal, and conotruncal anomaly such as double outlet right ventricle or transposition of great artery (Van Mierop et al. 1972; Rose et al. 1975; Peoples et al. 1983; Harada 1992). However, among such abnormalities, persistent truncus arteriosus with common atrioventricular canal has not been included. In this communication, we describe an infant with polysplenia syndrome, common atrioventricular canal and persistent truncus arteriosus. This complex cardiac anomaly was detected by echocardiography on the first day of life and later verified at autopsy.

\section{Case Report}

An infant weighing $1.7-\mathrm{kg}$ was born at a gestational age of 32 weeks by

Received October 4, 1994; revision accepted for publication July 25, 1995.

Address for reprints: Kenji Harada, M.D., Department of Pediatrics, Akita University School of Medicine, 1-1-1 Hondo, Akita 010, Japan. 
cesarean section because of fetal distress. The Apgar scores were 1 and 5 at 1 and 5 min, respectively. An endotracheal intubation was promptly performed and cardiopulmonary resuscitation by assisted ventilation with a tube and bag was successful. Oxygen was administered for persistent cyanosis. A physical examination disclosed multiple congenital anomalies such as esophageal atresia with tracheo-esophageal fistula, anal atresia and duodenal atresia. Additionally, congenital heart disease was suspected by echocardiography. The infant was referred to our hospital for further cardiac evaluation.

On admission, a physical examination revealed a heart rate of 150 beats $/ \mathrm{min}$, and a grade $3 / 6$ systolic murmur was heard best at the lower left sternal border. A chest $\mathrm{x}$-ray examination showed cardiomegaly with slightly increased pulmonary vascular markings. An echocardiogram (Fig. 1a and b) and Doppler study demonstrated a common atrioventricular canal of the balanced type and a large common atrioventricular valve. There was a single semilunar valve and a single arterial trunk from which the aortic arch as well as the left pulmonary artery originated. Right pulmonary artery was absent. There was a severe atrioventricular valve incompetence and mild truncal valve regurgitation.

Soon after the transfer, the infant developed increasing respiratory distress, and mechanical ventilation was instituted. Inspite of water restriction, and of administration of catecholamines, and diuretics along with other intensive care, the infant developed progressive ventilatory insufficiency and metabolic acidosis, and died $12 \mathrm{hr}$ later.

The postmortem examination disclosed heterotaxia of the abdominal organs with a central symmetrical liver and multiple spleens (Fig. 2c). The tracheobronchial anatomy was that of situs solitus with an eparterial bronchus on the right and a hyparterial bronchus on the left. The lungs, however, were bilaterally trilobed. Situs solitus was also anatomically suggested by the site of morphologically characterized right and left atrial appendages, that is, the right atrial appendage on the right side and the left one on the left side. The atrial septum was deficient and was represented only by an abnormal muscular band. The right superior vena cava was normal and the left superior vena cava was not persistent. The coronary sinus was absent. There was a common atrioventricular canal of the balanced type with a nodular and polypoid common atrioventricular valve. The right-sided anterior chamber was heavily trabeculated and appeared morphologically to be the right chamber, and the left-sided posterior chamber the left ventricle (Fig. $2 b$ ). There was a single arterial trunk with a left aortic arch from which arose the left pulmonary artery without right pulmonary artery. A major aorto-pulmonary collateral artery from the ascending aorta supplied the right lung (Fig. 2a). The truncal valve was tricuspid without truncal leaflet thickening. Moreover, the infant had esophageal atresia with a tracheoesophageal fistula,duodenal atresia at the papilla Vater area, malrotation of intestine, and cystic change of the left kidney. 


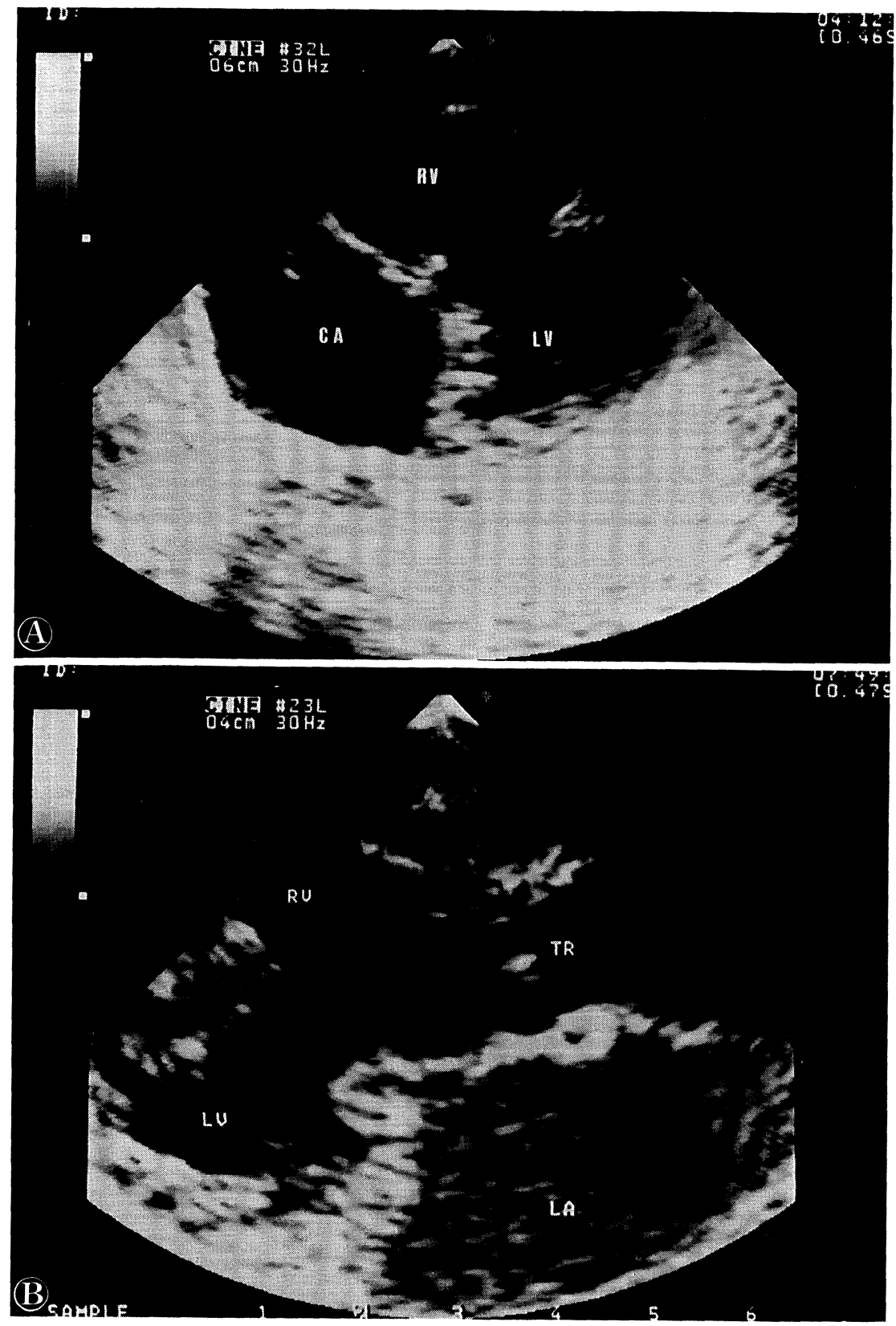

Fig. 1. A: Two-dimensional echocardiogram, apical four-chamber view.

B: Two-dimensional echocardiogram, long-axis view. CA, common atrium; $R V$, right ventricle; LV, left ventricle; LA, left-sided atrium; TR, persistent truncus arteriosus. 
H. Arai et al.
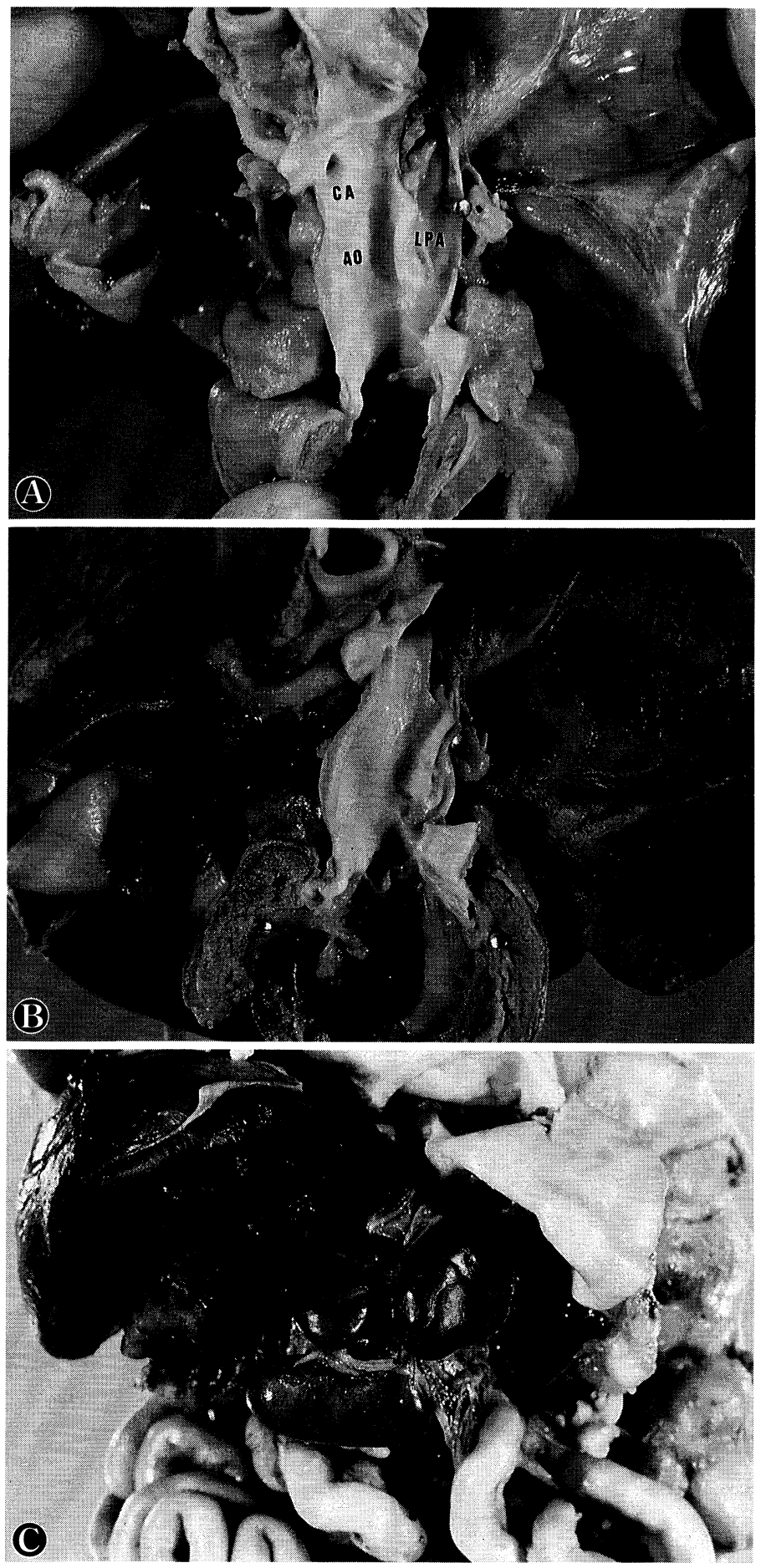

Fig. 2. 


\section{Discussion}

The association of a conotruncal anomaly with polysplenia syndrome is well known. However, Peoples et al. (1983) reviewed 146 cases of polysplenia syndrome from the literature and found that none had persistent truncus arteriosus. The term persistent truncus arteriosus is herein used to refer to those hearts from which a single arterial trunk originates which, in turn, gives rise to the systemic, pulmonary, and coronaryarterial circulation (Thiene et al. 1976; Calder et al. 1976; Crupi et al. 1977; Stark et al. 1978; Ceballos et al. 1983; Butto et al. 1986). In this early classification of persistent truncus arteriosus, Collett and Edwards (1949) reported 19 specimens with a common atrioventricular valve and a single ventricle. However, Van Praagh and Van Praagh (1965) denied this association in a later review of many of the same specimens. To our knowledge, this is the first report describing that polysplenia is associated with common atrioventricular canal and persistent truncus arteriosus, which was echocardiographically identified and anatomically proved. Persistent truncus arteriosus has long been the subject of fairly extensive description and discussion (Collett and Edwards 1949; Van Praagh and Van Praagh 1965; Calder et al. 1976; Thiene et al. 1976; Crupi et al. 1977; Stark et al. 1978; Ceballos et al. 1983; Salazar et al. 1985; Butto et al. 1986). While truncal valve morphology is quite variable (Calder et al. 1976) and associated coronary artery and aortic arch anomalies are common

\begin{tabular}{lccccccc} 
TABLE 1. & $\begin{array}{c}\text { Previously reported } \\
\text { atrioventricular valve }\end{array}$ & persistent & truncus & arteriosus & with & common \\
& Age (death) & Sex & Type & CAVC & CAVVR & $\begin{array}{c}\text { Splenic } \\
\text { anomaly }\end{array}$ \\
\hline & 1 month & Female & A-1 & - & Unknown & - \\
Van Praagh and & & & & & & - \\
Van Praagh (1965) & Unknown & Unknown & Unknown & + & Unknown & - \\
Ceballos et al. (1983) & Unknown & Unknown & Unknown & + & Unknown & - \\
Butto et al. (1986) & Unk days & Male & A-2 & + & + & Asplenia \\
Gumbiner et al. (1991) & 6 day & Male & A-3 & + & + & Polysplenia \\
Our case & 1 day & Mase &
\end{tabular}

Type, classification of turncus arteriosus by Van Pragh et al.; CAVC, common atrioventricular canal; CAVVR, common atrioventricular valve regurgitation.

Fig. 2. A: The heart was opened from the right ventricle into the truncus. The truncus produces a predominant aorta (AO) and small left pulmonary arteries (LPA) with absence of right pulmonary artery, implying absence of the aortopulmonary septum. A collateral artery (CA) supplies the right lung was not receive a pulmonary artery branch from the truncus.

B: The heart was opened from the left ventricle. The atrioventricular canal defect with common atrioventricular valve is obvious.

C: Multiple spleens. 
(Collett and Edwards 1949; Calder et al. 1976; Crupi et al. 1977; Ceballos et al. 1983; Butto et al. 1986), persistent truncus arteriosus is seldom associated with significant malformations of atrioventricular valves, and its association with common atrioventricular canal is very rare. There have been five cases (Van Praagh and Van Praagh 1965; Ceballos et al. 1983; Butto et al. 1986; Gumbiner et al. 1991) including our present case, in which persistent truncus arteriosus was associated with common atrioventricular valve, and, four of these cases were common atrioventricular canal with persistent truncus arteriosus (Table 1). The prognosis of this combination is poor and three of these cases did not survive beyond 30 days of age. In our present case, a severe common atrioventricular valve regurgitation was identified as in previously reported cases. The poor prognosis of this association may be attributed to severe incompetence of the common atrioventricular valve. It appears that persistent truncus arteriosus with common atrioventricular canal causes a high incidence of atrioventricular regurgitation.

It is clear from our review of previous reports that persistent truncus arteriosus is associated only rarely with common atrioventricular canal. The persistent truncus arteriosus is extremely rare in the setting of polysplenia syndrome, but the present case report demonstrates that these anomalies may, at times, occur.

\section{References}

1) Butto, F., Lucas, R.V. \& Edwards, J.E. (1986) Persistent truncus arteriosus: Pathologic anatomy in 54 cases. Pediatr. Cardiol., 7, 95-101.

2) Calder, L., Van Praagh, R., Van Praagh, S., Sears, W.P., Corwin, R., Levy, A., Keith, J.D. \& Paul, M. (1976) Truncus arteriosus communis: Clinical, angiocardiographic, and pathologic findings in 100 patients. Am. Heart J., 92, 23-38.

3) Ceballos, R., Soto, B., Kirklin, J.W. \& Bargeron, L.M. (1983) Truncus arteriosus: An anatomical-angiographic study. $B r$. Heart J., 29, 589-599.

4) Collett, R.W. \& Edwards, J.E. (1949) Persistent truncus arteriosus: A classification according to anatomic type. Surg. Clin. North. Am., 29, 589-599.

5) Crupi, G., Macartney, F.J. \& Anderson, R.H. (1977) Persistent truncus arteriosus: A study of 66 autopsy cases with special reference to definition and morphogenesis. Am. J. Cardiol., 40, 569-578.

6) Harada, K. (1992) Atrial morphology and cardiac anomalies in asplenia and polysplenia syndrome. Akita. J. Med., 19, 239-248. (in Japanese with English abstract)

7) Gumbiner, C.H., McManus, B.M. \& Laston, L.A. (1991) Associated occurrence of persistent truncus arteriosus and asplenia. Pediatr. Cardiol., 12, 192-195.

8) Peoples, W.N., Moller, J.H. \& Edwards, J.E. (1983) Polysplenia: A review of 146 cases. Pediatr. Cardiol., 4, 129-137.

9) Rose, V., Izukawa, T. \& Mose, C.A.F. (1975) Syndromes of asplenia and polysplenia: A review of cardiac and non-cardiac malformations in 60 cases with special reference to diagnosis and prognosis. Br. Heart J., 37, 840-852.

10) Salazar, J., Felipe, J., Garcia, M.D., Rios, M.J. \& Garcia, B. (1985) Monoventricular origin of truncus arteriosus communis. Acta Cardiol., 40, 425-431.

11) Stark, J., Gandhi, D., de Leval, M., Macartney, F. \& Taylor, J.F.N. (1978) Surgical treatment of persist truncus arteriosus in the first year of life. Br. Heart J., 40, 12801287. 
12) Thiene, G., Bortolotti, U., Gallucci, V., Terribile, V. \& Pellegrino, P.A. (1976) Anatomical study of truncus arteriosus communis with embryological and surgical considerations. Br. Heart J., 38, 1109-1123.

13) Van Mierop, L.H.S., Gessner, I.H. \& Schiebler, G.L. (1972) Asplenia and polysplenia syndrome. Birth Defects, 8, 74-82.

14) Van Praagh, R. \& Van Praagh, S. (1965) The anatomy of common aorticopulmonary trunk (truncus arteriosus communis) and its embryologic implications: A study of 57 necropsy cases. Am. J. Cardiol., 16, 406-425. 